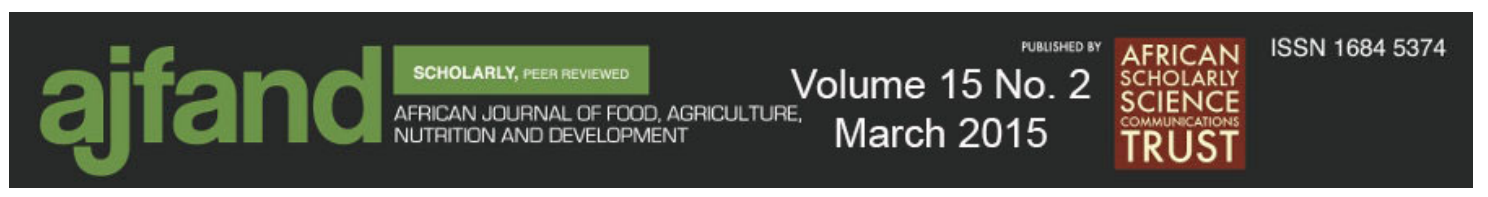

\title{
EFFECTS OF SUCROSE AND VEGETABLE OIL ON PROPERTIES OF NATIVE CASSAVA (Manihot esculenta CRANTZ) STARCH-BASED EDIBLE FILMS
}

\author{
Nindjin $\mathrm{C}^{1,3^{*}}$, Beyrer $\mathrm{M}^{2}$ and $\mathrm{GN}$ Amani ${ }^{1}$
}

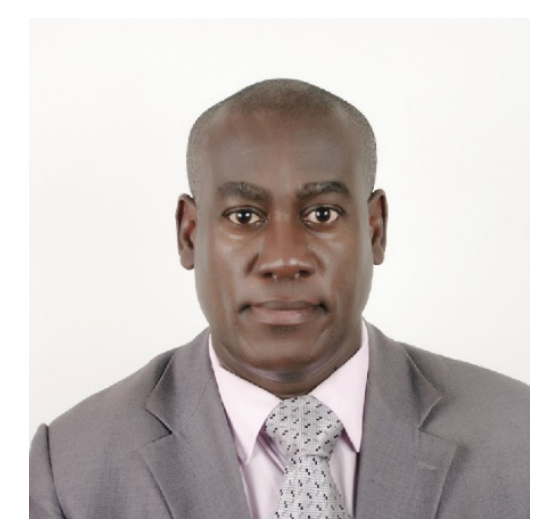

Charlemagne Nindjin

${ }^{*}$ Corresponding author email: charlemagne.nindjin@yahoo.fr

${ }^{1}$ Training and Research unit in Food Science and Technology, University Nangui Abrogoua (former University of Abobo-Adjamé), B.P. 801 Abidjan 02, Côte d'Ivoire

${ }^{2}$ Institute of Life Sciences, University of Applied Sciences Western Switzerland, Route du Rawyl 47 CH-1950 Sion 2, Switzerland

${ }^{3}$ Department of Biodiversity and Food Security, Centre Suisse de Recherches Scientifiques (CSRS) en Côte d'Ivoire, 01 BP 1303 Abidjan 01, Côte d'Ivoire 


\section{ABSTRACT}

Biopolymer films and coatings from polysaccharides, proteins and lipids, formulated either with one or more components have the potential to control mass transfer and thus extend food shelf life. Due to the increase in the price of starches from traditional sources (such as corn), native or modified cassava starch has been recently considered as an economic alternative for the food industry. In this study, the effects of sucrose and vegetable oil as natural, cheaper and available plasticizer and moisture barrier material, on optical, mechanical and water barrier properties of cassava starch-based films were analyzed. Visual appearance and the polarized light microscopy data revealed that oil made the film opaque, and larger oil droplets were formed as sucrose content increased. The modification of the starch network, when sucrose was used at higher concentrations (15-20\%), in combination with oil, weakened mechanical and water barrier properties. The behaviour of sucrose added to aqueous starch solution, in combination with oil, favored a development of larger droplets observed by polar microscopy, and which made the film matrix discontinuous and irregular. The heterogeneity of the film structure made the composite films fragile and facilitated water vapor diffusion. However, the film formulations containing low sucrose concentration ( $\leq 10 \%)$ and an oil content of $10 \%$, significantly reduced water vapor permeability, in comparison to film without oil. The formulations of composite film with low content of sucrose $(\leq 10 \%)$ showed smaller lipidic droplets and a structure more homogeneous by polar microscopy. Film thickness increased with total solid content in film matrix, and this effect was significantly pronounced as higher sucrose content (15-20\%) was present with added vegetable oil. In addition to the linking with total solid content, this study revealed that, the thickness of films depends on reordering of molecular chains to form a more compact matrix in composite starch films, and this results in further increase film thickness. The composite films, thicker than the film control, were less cohesive due to less affinity between matrix components, and this resulted in anti-plastifiant behaviour of sucrose. Thus, sucrose used at higher levels, in combination with oil, induced negative effects on mechanical and water barrier properties of polysaccharide film. This study revealed the impact of the nature of molecular interactions on the structural characteristics and functional properties of composite matrix.

Key words: cassava, biofilm, starch, sucrose, lipid 


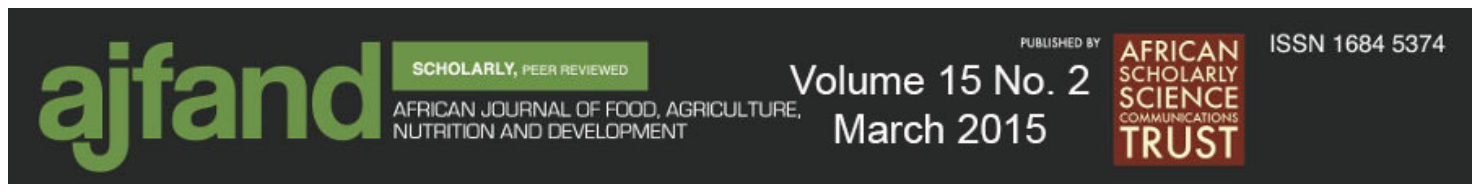

\section{INTRODUCTION}

Starch is one of the polysaccharides frequently used to develop edible films, as it is a natural polymer capable of forming a continuous matrix and it is a renewable and abundant resource [1]. In particular, cassava is a good commercial cash crop and a major source of good quality starch [2], which is cheaper than other starches usually used in the food industry. The addition of a plasticizer agent to edible films is required to overcome film brittleness, caused by high intermolecular forces (polymer molecules joined by covalent bonds, hydrogen bonding and/or Van der Waal forces). The most commonly used plasticizers are polyols, such as sorbitol and glycerol. They prevent cracking of the film during handling and storage [3]. Moreover, sucrose, which is a non-toxic, edible, and low-cost biodegradable raw material, has been demonstrated to have a higher plasticizing efficacy when compared to sorbitol and glycerol [4]. However, evidence of sucrose crystallization during storage has been reported as the material changes from malleable to brittle [5]. On the other hand, as well known hydrocolloid films are characterized by their good gas barrier properties but poor water vapor permabilities. To overcome these impairments, hydrophobic properties of lipids, such as beeswax or carnauba wax, are exploited for their great water barrier properties [6]. Vegetable oils, as natural hydrophobic material highly available and affordable, have been studied by being incorporated in hydrophilic films to modulate the water vapor barrier properties of protein [7] and polysaccharide-based films [8]. Most fatty acids derived from vegetable oils are considered GRAS (generally recognized as safe) substances and have been suggested as substitutes for the petroleum-based mineral oils used in the preparation of edible coatings [9]. However, it has also been reported that incorporation of certain lipid materials into hydrophilic suspensions have an adverse effect on the mechanical and optical properties of the resulting films [10]. Thus, the homogeneity and integrity of oilcontaining polysaccharide film closely depend on the miscibility of hydrophobic molecules into hydrophilic matrix, leading to laminating structure or emulsified blend [11]. In fact, some fatty acids are unable to form a continuous, cohesive matrix, and the resulting films are fragile. Fatty acids showing unsaturations, polarities and higher length of aliphatic chain lead to a much better homogeneity of hydrocolloïdal matrix than fattyacids presenting shorter and saturated chain [11]. For this purpose, some monounsaturated fatty acid, like oleic acid, added to polymer matrix provided slight irregularities in the matrix which are greatly accentuated when the non polar lipid as beeswax was present [7].

Among the different additives used in film forming, natural plasticizers and hydrophobic substances with good availability, low price and much better miscibility in polymer matrix should be chosen in order to increase the potential for edible film-forming applications. Sucrose and vegetable oil rich in unsaturated fatty-acid are natural additive substances and can fulfill these requirements in general. The aim of this work is to study the functionality of vegetable oil and sucrose in coatings made from cassava starch used as polysaccharide matrix and to test the effectiveness of their association in edible film matrix. The target of this investigation is to increase the potential applications of a staple tropical crop (cassava root), such as starch-based edible film, using natural and affordable improving agents. 


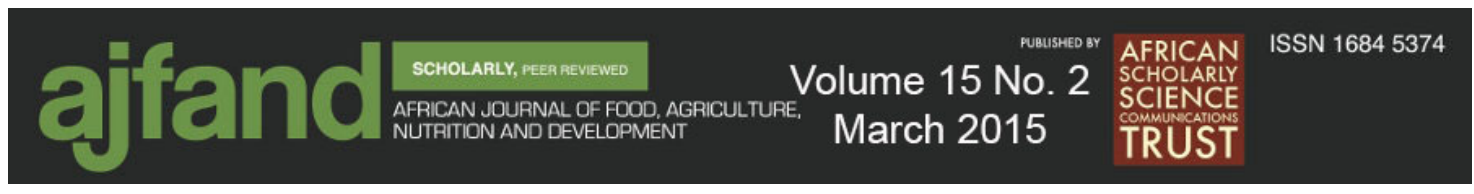

\section{MATERIALS AND METHODS}

\section{Materials}

The native starch used was obtained by cold water extraction [12] from a cassava variety 98/0325 belonging to the genotype collection of the International Institute of Tropical Agriculture (IITA, Nigeria). The cassava plant was harvested, at maturity, after 12 months of plantation. Pure sucrose used as plasticizer and potassium sorbate used as preservative agent of suspensions were obtained from VWR International AG Switzerland. The vegetable oil was groundnut oil (Suprema ${ }^{\circledR}$, Migros, Switzerland) and was used as hydrophobic material. It was purchased from a local supermarket and was mainly composed of mono-unsaturated fatty acids (54\% of total lipids), and also contained poly-unsaturated fatty acids ( $28 \%$ of total lipids) and saturated fatty acids ( $16 \%$ of total lipids).

\section{Film preparation}

Starch $8 \mathrm{~g}$ was added to a glass beaker containing $200 \mathrm{ml}$ of demineralized water to obtain a suspension of $4 \%(\mathrm{w} / \mathrm{w})$ of starch, as recommended by Mali et al. [13]. Variable quantities: $0 \%, 5 \%, 10 \%, 15 \%$ and $20 \%$ (w/w, dry starch basis) of sucrose and $0.4 \mathrm{~g}$ of potassium sorbate $(0.2 \%$ of the suspension) were added to the suspension. The starch pastes were gelatinized by heating the mixtures gradually from $30^{\circ} \mathrm{C}$ to $90{ }^{\circ} \mathrm{C}$ during 1 h, with constant stirring (700 rpm), on a hot plate (Ikamag ${ }^{\circledR}$, model RET-GS). During the gelatinization procedure, the beaker was covered with aluminium foil, in order to avoid evaporation of water. The final temperature of $90{ }^{\circ} \mathrm{C}$ was maintained for $10 \mathrm{~min}$. At this phase, $10 \%$ (w/w, dry starch basis) of vegetable oil was added to the mixture with constant stirring to move towards a more homogeneous emulsion, even if emulsion is inclined to break after the drying step. No emulsifier was used in this study. About $18 \mathrm{~g}$ of gelatinized suspension were carefully poured onto the surface of Petri dishes $(9 \mathrm{~cm}$ diameter) to minimize the formation of air bubbles included in the film. The starch-oil mixtures were then dried in a ventilated oven (Mazzali ${ }^{\circledR}$, Labotest, Italy) for $48 \mathrm{~h}$, under controlled condition ( $25^{\circ} \mathrm{C}$ and $60 \%$ of moisture). The films obtained were peeled off the plate. The isolated films were equilibrated for $48 \mathrm{~h}$, at $25{ }^{\circ} \mathrm{C}$ and $60 \%$ relative humidity $(\mathrm{RH})$, before being tested.

\section{Analytical methods}

\section{Water content}

The water content of the film was determined by measuring weight loss of the film upon drying in a ventilated oven (Renggli ${ }^{\circledR}$, Salvis AB) at $105^{\circ} \mathrm{C}$ until constant weight was achieved (dry sample weight). Samples were analyzed in triplicate.

\section{Microscope observations}

The surfaces of samples were examined with a polarized light microscope (Zeiss, model Axioplan, Germany) at a magnification of $100 x$ and using the microscopic analysis software Analysis ${ }^{\circledR}$ (Software Imaging System, GmbH), in order to determine possible agglomerations of the particles or the homogeneity of films. 


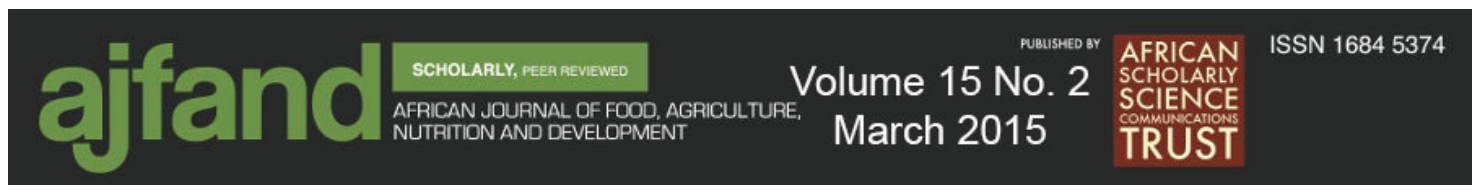

\section{Thickness measurements}

The thickness of the films was determined with a manual micrometer (Mitutoyo ${ }^{\circledR}$, Japan) at 6 random positions of the film, with an accuracy of $\pm 0.01 \mathrm{~mm}$.

\section{Mechanical Properties}

The tensile properties were studied using a TA.XT-Plus Stable Micro Systems texture analyzer (Surrey, England) as described by Mali et al. [14]. The experiments were performed at room temperature $\left(\sim 25^{\circ} \mathrm{C}\right)$ and ambient relative humidity ( $\left.\sim 45 \% \mathrm{RH}\right)$. Eight sample strips ( $2.5 \mathrm{~cm}$ wide and $10 \mathrm{~cm}$ long) of each formulation were cut and clamped between self tightening roller grips. Thus, each formulation was analyzed eight times. Force $(\mathrm{N})$ and deformation $(\mathrm{mm})$ were recorded during an extension at $1 \mathrm{~mm} . \mathrm{s}^{-1}$, for $20 \mathrm{~mm}$ of distance and with an initial distance between the grips of $50 \mathrm{~mm}$. The parameters determined were stress at break $(\mathrm{N})$ and strain at break $(\mathrm{mm})$. Stress at break and strain at break are referred to in the literature as tensile strength and elongation, respectively.

\section{Water vapor permeability}

Water vapor permeability (WVP) tests were conducted using ASTM method E96 with some modifications, described by Galdeano et al. [15]. Films were selected for WVP tests based on lack of physical defects such as cracks, bubbles, or pinholes. Each film sample was sealed with an adhesive (3M Scotch tape, Brazil) over a rectangular window into the lid of a plastic cup weighing $3-4 \mathrm{~g}$. Exposed surface was $0.0006 \mathrm{~m}^{2}(0.02 \mathrm{~m} \mathrm{x}$ $0.03 \mathrm{~m}$ ). The depth of the cup was $0.05 \mathrm{~m}$. To maintain $75 \% \mathrm{RH}$ gradient across the film, anhydrous calcium chloride $(0 \% \mathrm{RH})$ was placed inside the cup and a sodium chloride saturated solution (75\% RH) was used in the desiccator. The distance between the film and the calcium chloride layer was $1 \mathrm{~cm}$. The $\mathrm{RH}$ inside the cup was lower than on the outside, and water vapor transport was determined from the weight gain of the cup. After steady state conditions were reached (about $2 \mathrm{~h}$ ), one weight measurement per day was made over eight days. Changes in the weight of the cup were recorded (gram or g) to the nearest $0.0001 \mathrm{~g}$ and plotted as a function of time (seconds or s). The slope of each line was calculated by linear regression $\left(r^{2} \geq 0.99\right)$ and the water vapor transmission rate (WVTR) (g.s $\mathrm{s}^{-1} \cdot \mathrm{m}^{-2}$ ) was calculated from the slope of the straight line (g.s) divided by the transfer area $\left(\mathrm{m}^{2}\right)$. After the permeation tests (WVTR), film thickness was measured and WVP $\left(\mathrm{g} \mathrm{Pa}^{-1} \mathrm{~s}^{-1} \mathrm{~m}^{-1}\right)$ was calculated as WVP $=\left[\mathrm{WVTR} / \mathrm{S}\left(\mathrm{R}_{1}-\mathrm{R}_{2}\right)\right] \mathrm{d}$; where $\mathrm{S}$, the saturation vapor pressure of water $(\mathrm{Pa})$ at the test temperature $\left(25^{\circ} \mathrm{C}\right)$, was $3170 \mathrm{~Pa}, \mathrm{R}_{1}$ was the $\mathrm{RH}$ in the desiccator, $\mathrm{R}_{2}$ was the $\mathrm{RH}$ in the cup and $\mathrm{d}$ was the film thickness (m). Under these conditions, the driving force $\left[\mathrm{S}\left(\mathrm{R}_{1}-\mathrm{R}_{2}\right)\right]$ was $3095 \mathrm{~Pa}$. All tests were conducted in duplicate.

\section{Statistical analysis}

The software SAS ${ }^{\circledR}$ (SAS Institute Inc., Cary, NC, USA) version 9.2 was used for all statistical analysis. Means, standard deviation and Duncan's Multiple Range test for means comparison were applied. The significance level used was 0.05. 


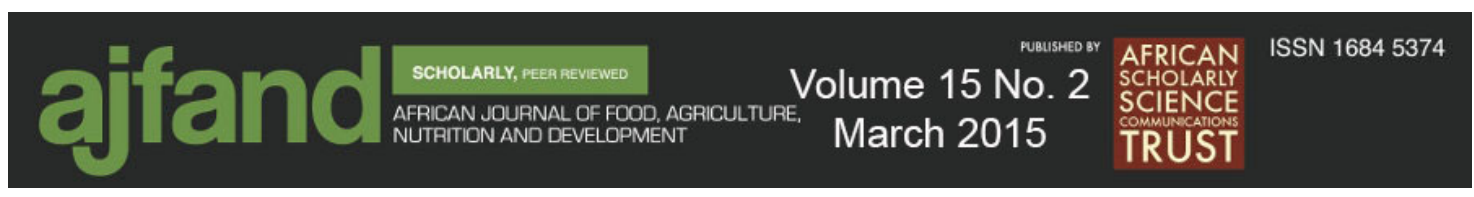

\section{RESULTS}

\section{Structural characterization of films}

More or less homogeneous, thin, flexible and transparent films were obtained from gelatinized starch slurries with and without additives (Fig. 1). Films without edible oil appeared transparent and smooth (Fig. 1a, b), but when oil was added, the resulting films became opaque (Fig. 1c, d, e, f, g). In addition, the surface of these oil-containing films showed some oil stains, due to phase separation during drying steps. These films were more oily to the touch, less homogeneous than films without oil and showed cracks (Fig. $1 \mathrm{e}, \mathrm{f}, \mathrm{g})$ when films were transferred from the oven area $(60 \% \mathrm{RH})$ to ambient conditions showing a relative humidity more dried $(45 \% \mathrm{RH})$.

In general, the water content of films did not differ significantly, except films containing high level of sucrose (15-20\%) showing lower relative humidity, due to their higher solid matter content (Fig. 2).

Figure 3 shows that film thickness tended to increase with total solid content in film matrix, and this effect was significantly pronounced when relatively high sucrose content was present with added vegetable oil, i.e from $10 \%$ sucrose content and beyond. In fact, when $20 \%$ sucrose was present in film matrix without added vegetable oil (Oil 0\%-Suc $20 \%$ ), the thickness of this film was not significantly different to that of the control (Oil $0 \%$-Suc $0 \%$ ). However, in presence of vegetable oil, the thickness of the film containing $20 \%$ sucrose (Oil 10\%-Suc 20\%) became significantly higher $(p<0.05)$ to that of the corresponding control (Oil 10\%-Suc 0\%).

The light microscopy showed differences in the appearance of the starch-oil composite films (Fig. 4). Without oil, the films appeared more transparent and homogeneous (Fig. $4 a, b)$, but when oil was added, the resulting films were opaque and showed oil droplets (Fig. 4c, d, e, f, g). When more than 10\% sucrose was added, the sizes of droplets seemed relatively larger than those observed on the surface of films containing lower sucrose content. 

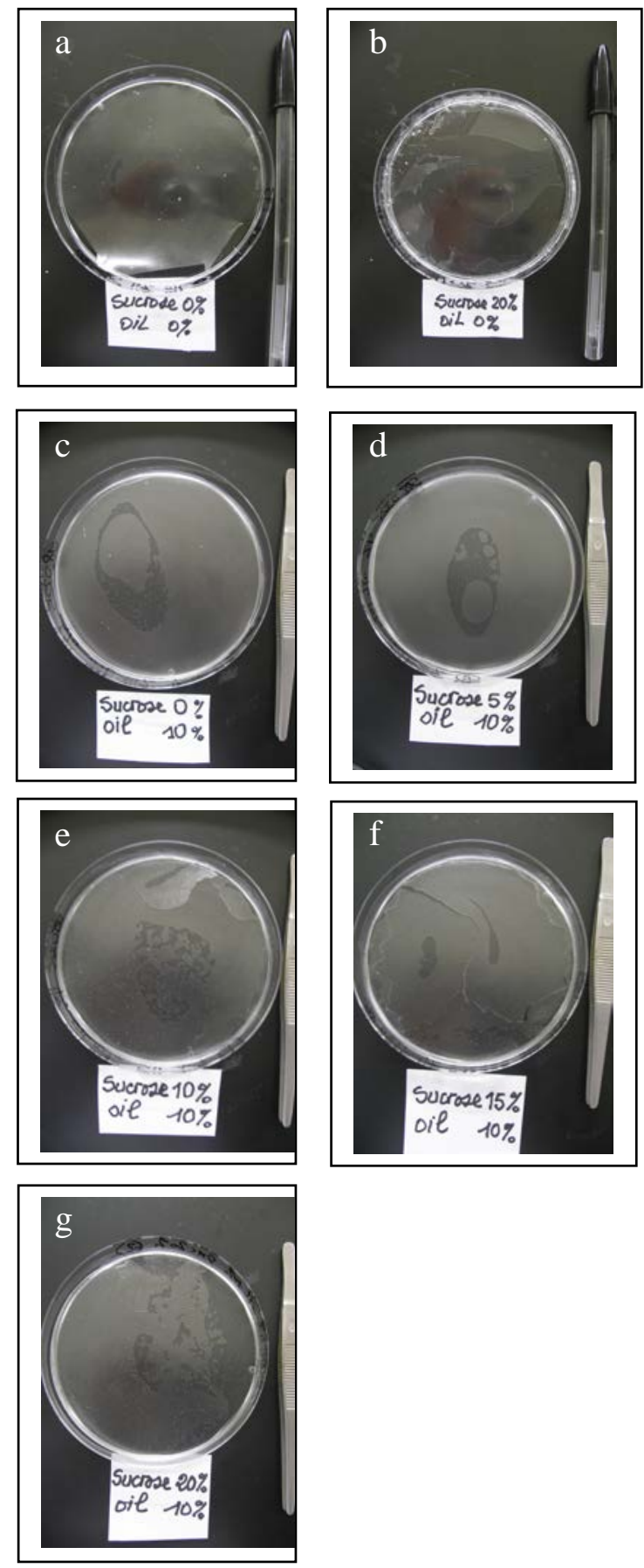

Figure 1: Visual appearance of films*

*(a) and (b) illustrate the effect of sucrose used as only additive. (c), (d), (e), (f) and $(\mathrm{g})$ show the effects of combination with both sucrose and vegetable oil. 


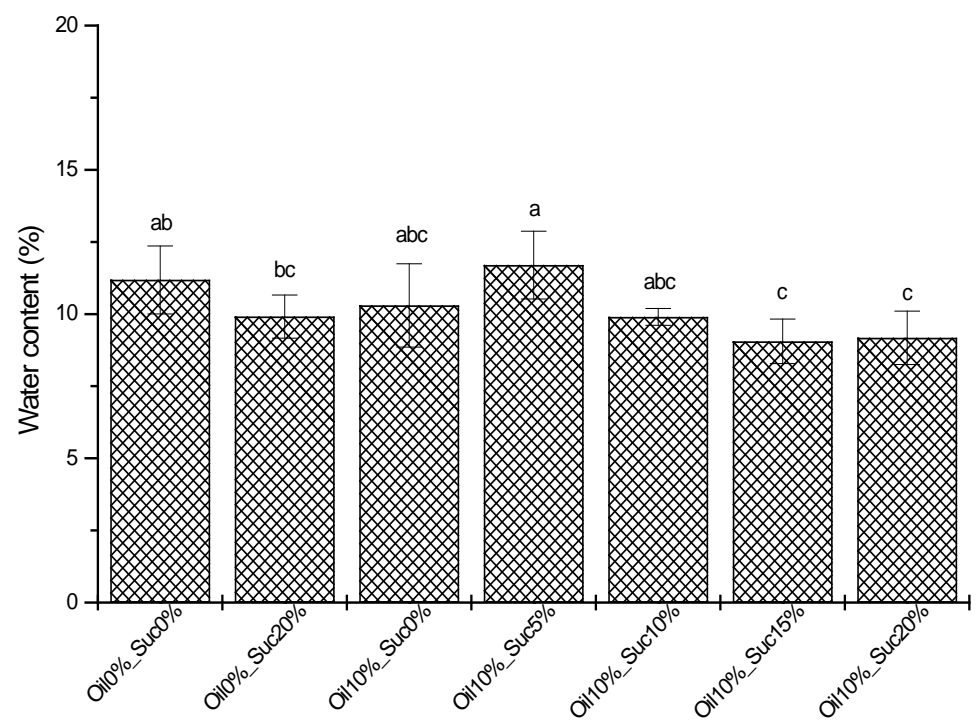

Film formulations

Figure 2: Influences of sucrose and vegetable oil on water content of films

\section{Mechanical properties}

The mechanical properties (tensile strength at break and elongation at break) of films were affected by sucrose and oil addition. Sucrose significantly decreased the tensile strength $(p<0.05)$, and the effect was more pronounced as both sucrose and vegetable oil were added together (Fig. 5). In contrast, adding $10 \%$ of oil without sucrose did not affect significantly ( $p>0.05)$ the tensile strength of the starch film (Fig. 5).

Concerning the elongation at break, the effects were less pronounced. Figure 6 shows that extensibility of sucrose-starch film and oil-starch film did not differ significantly ( $p>0.05$ ) from respective control samples, as vegetable oil or sucrose was present alone in the starch film matrix. However, once both ingredients were added, the extensibility of plasticized films significantly decreased $(\mathrm{p}<0.05)$, as higher sucrose fractions (15$20 \%$ ) were introduced. Moreover, adding sucrose at lower concentrations (5-10\%) did not significantly modify $(p>0.05)$ the elongation between the plasticized and unplasticized oil-starch films. 


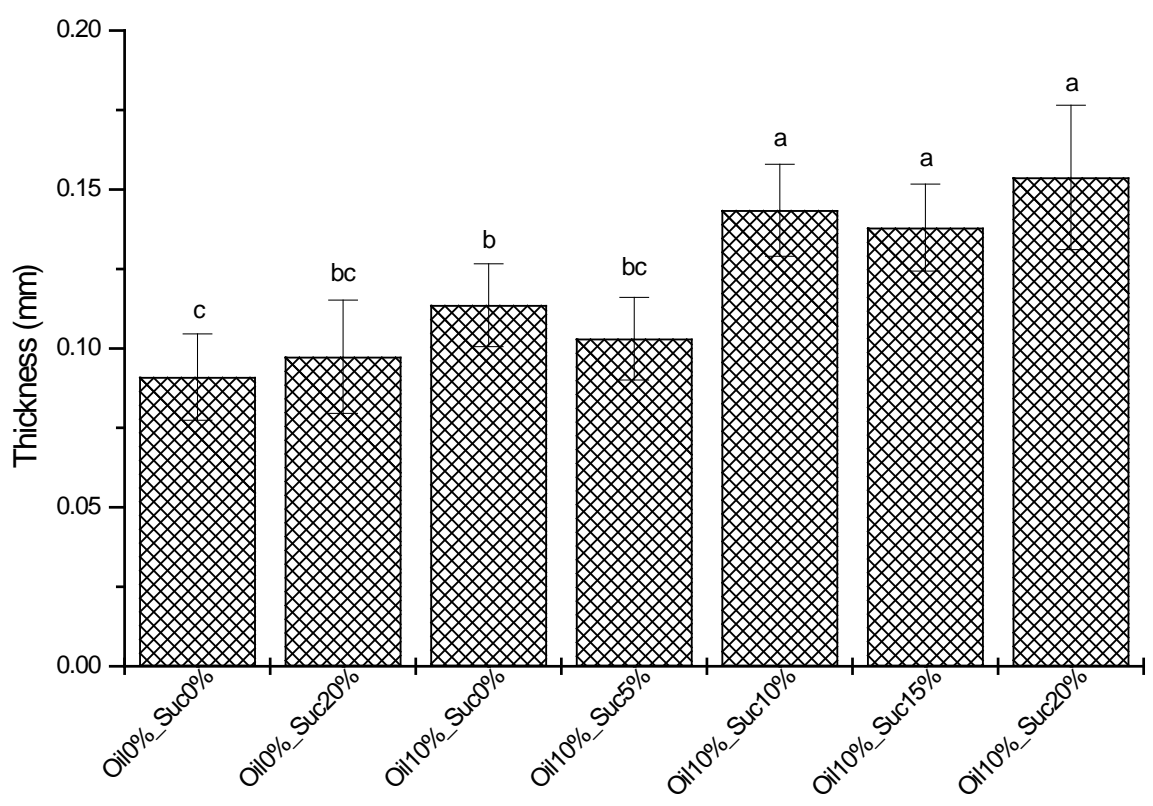

Film formulations

Figure 3: Thickness of films
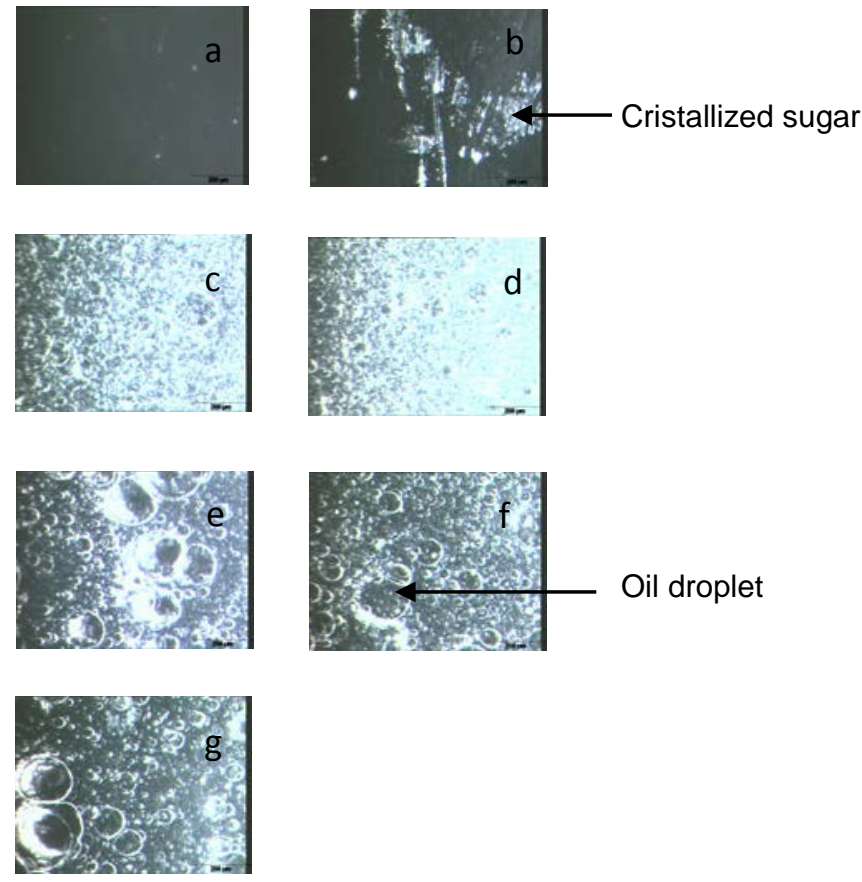

Figure 4: Microscopic appearance of films (polarized light microscopy, 100x)* *(a) $0 \%$ oil - $0 \%$ sucrose, (b) $0 \%$ oil - 20\% sucrose, (c) $10 \%$ oil - $0 \%$ sucrose, (d) $10 \%$ oil 5\% sucrose, (e) $10 \%$ oil - 10\% sucrose, (f) $10 \%$ oil - 15\% sucrose, (g) $10 \%$ oil - $20 \%$ sucrose. The amount of oil and sucrose added is expressed as percentage dry starch basis. 


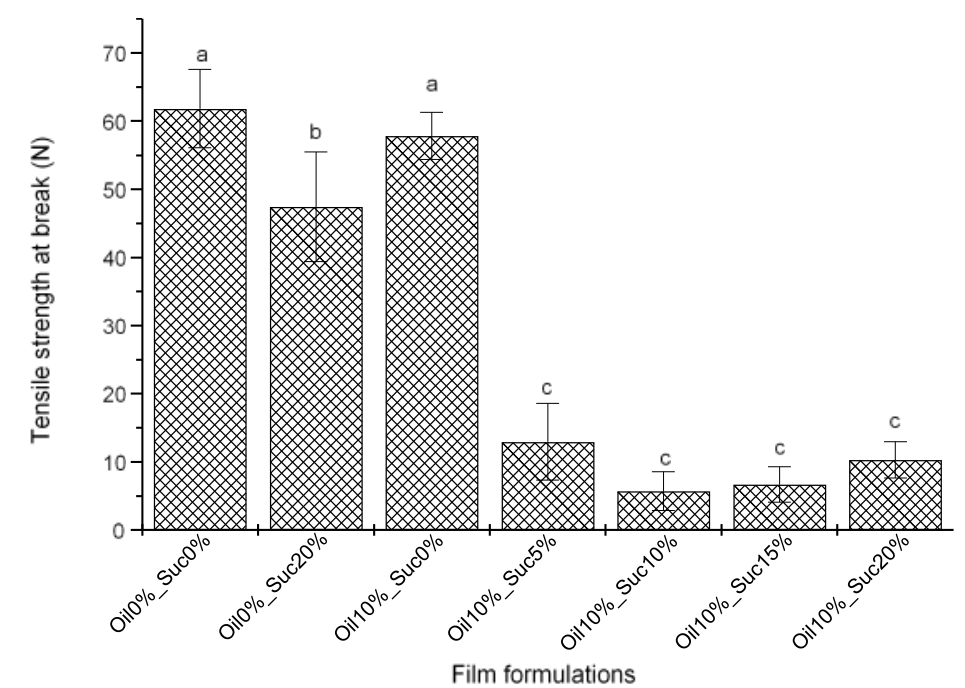

Figure 5: Tensile strength at break of films

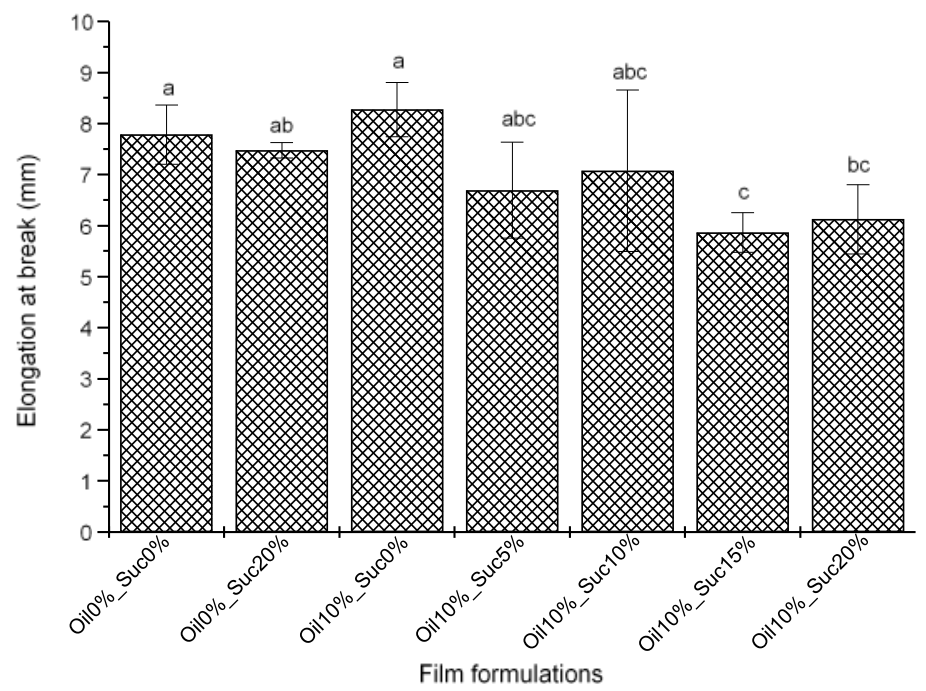

Figure 6: Elongation at break of films

\section{Water vapor permeability}

Figure 7 shows WVP of individual vegetable oil-starch films and sucrose-starch films and also of the composite films containing both vegetable oil and sucrose. A sucrose content of $20 \%$ (without oil) in the film-forming matrix did not modify the WVP of films. On the other hand, a vegetable oil content of $10 \%$ without sucrose or in combination with sucrose added at low concentrations (5-10\%) significantly reduced $(p<0.05)$ water vapor permeability of films. However, the water barrier effect, caused by vegetable oil, was greatly weakened when the added concentrations of sucrose were relatively high (1520\%). 


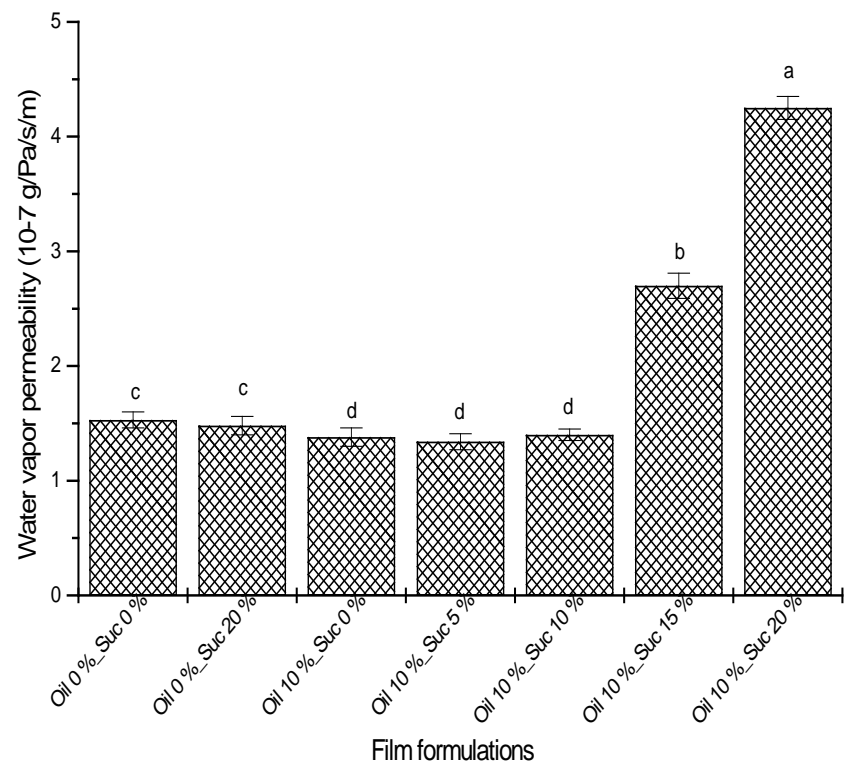

Figure 7: Water vapor permeability of films

\section{DISCUSSION}

\section{Structural characterization of films}

Similar findings, like those in this present study, have been reported by Mali et al. [16], suggesting that sucrose molecules can form crystals that affect the film-forming matrix. The matrix of the film becomes more dense [16], which makes it more brittle under drying ambient conditions. Sucrose crystallization in starch films has been also reported in previous studies [5].

Other authors, like Veiga-santos et al. [17] also observed an increase of film thickness with addition of sucrose. Similar findings reported that films with the same total solid content did not differ significantly in thickness, and increasing total solid thickened the films [18]. Moreover, this present study showed that, in addition to the total solid content, the thickness of films depends on reordering of molecular chains to form a more compact matrix in composite starch films. That explains why, in absence of added oil, sucrose did not significantly modify film thickness, but using it in combination with oil, further increased film thickness in comparison with corresponding control. Another study [19] also reported that crystal formation could arise from rearrangement of randomly bound sugar molecules. This molecular reordering of starch suspension components, in the present study, would generate the bulky structure of the composite oil-sucrose-starch films that appeared more and thick as sucrose content increased.

Furthermore, the present study showed that increasing sucrose content in the matrix containing vegetable oil enlarges the sizes of droplets. This result was related to the effect of continuous phase viscosity on breaking of the dispersed phase droplets. As reported in the literature, breaking of the droplets during emulsification results from shear effects 
in turbulent flow provided by a stirrer [20]. Thus, adding sucrose might have increased the viscosity of starch paste, as mentioned by other authors [21]. Indeed, the increase of the viscosity as sucrose content increased could have hindered the breaking of oil droplets into smaller ones, which could explain the larger sizes of oil droplets in the resulting films.

\section{Mechanical properties}

The present study showed that relatively high content of sucrose reduced the strength and elongation of resulting films, and the effect was enhanced when both ingredients, sucrose and vegetable oil, were added. Similar findings about the effects of plasticizers on tensile strength of films have previously been reported. Indeed, when sucrose [4] or soybean oil [22] was added to starch based films, the resistance to tensile strength was reduced. Veiga-Santos et al. [5] also reported lower tensile strength in cassava starch films when sucrose, propylene glycol or soybean oil was added. According to Guilbert and Gontard [23], plasticization decreases the intermolecular forces between polymer chains, and consequently, the overall cohesion and the glass transition temperature are reduced. The matrix of the film becomes less dense, facilitating movements of polymer chains under stress, therefore decreasing the film resistance [16] and improving film flexibility and extensibility [24]. As expected, the variables that increased elongation at break in general, also decreased tensile strength [17]. However, this trend was not observed in the present study. In fact, using sucrose and vegetable oil together in starch film forming decreased the film resistance, as well as its extensibility. As also reported by Cao et al. [25], sucrose made gelatin film more fragile by decreasing the tensile strength and elongating at break. Furthermore, these authors notified that sucrose made soy protein isolate film more brittle, due to the fact that the sucrose monomers $\alpha$-D-glucose and $\beta$ D-fructose have a bulky ring structure [25]. In fact, an efficient interaction with polymeric chains was more difficult to make due to the molecule structure of this sugar (ring chain) compared to straight chains of other plasticizers (glycerol, sorbitol) [15]. Moreover, adding a lipidic molecule with its long aliphatic chain might increase this stereo hindrance, previously created by the sucrose molecule. A resulting bulky blend of molecules forming the composite film matrix could contain porous areas, which could weaken the film cohesion. An additional phenomenon explaining the brittleness of sucrose-containing films could be related to the crystallization process of sucrose chains during storage. Especially when water content is low, sucrose molecules can be associated, forming crystals that could affect the film-forming matrix, as reported by Veiga-Santos et al. [17]. For this purpose, these authors reported that crystallinity was observed during storage, due to sucrose addition to cassava starch-xanthan gum films, changing the material from malleable to brittle. In addition, Debeaufort and Voilley [26] suggested that the higher the strength and the elongation at break of the films, the smaller the fatty inclusions and the more homogeneous their distribution in hydrocolloid matrix. According to these authors, such matrix was more continuous and regular. In other terms, a heterogeneous film matrix seems to weaken the mechanical properties of films. This assertion was confirmed in the present study. The films that contained many large lipid inclusions were also the most fragile, but the elongation was less affected compared to the tensile property. Contrary to previous findings, where sucrose increased elongation at break [5], this study showed that sucrose exhibited an antiplasticizing effect, and this behavior was more pronounced when sucrose and vegetable oil were present at the same 
time in the starch matrix, especially where sucrose fractions were relatively higher (1520\%). The antiplasticizing effect of sucrose on edible films has been also reported by Cao et al. [25]. The resulting bulky blend of molecules due to interacting effect of sucrose and vegetable oil in starch matrix could also explain why the increase of film thickness was significantly marked, as higher sucrose content $(\geq 10 \%)$ was present with added vegetable oil. This result shows that, in addition to the total solid content, the thickness of films depends on reordering of molecular chains to form a more compact matrix in composite starch films. Another study [27] also reported that crystal formation could arise from rearrangement of randomly bound sugar molecules. In the present study, this molecular reordering of starch suspension components would generate the bulky structure of the composite oil-sucrose-starch films that appeared more thick as sucrose content increased. That explains why film thickness increased with solid contents in the composite starch matrix.

\section{Water vapor permeability}

Some observations reported that lipid presence significantly decreased water vapor permeability (WVP) of starch based films due to its hydrophobicity [22]. However, using lipid in combination with other components showing less affinity, an opposite effect may be occurred, as observed in the present study. Indeed, oil-sucrose-starch films containing higher amounts of sucrose showed larger droplets. The reduction of the specific surfaces of the lipid phase with larger droplets possibly resulted in the reduction of water vapor barrier. Similar findings related to the formation of areas without any hydrophobic material in hydrocolloid matrix due to aggregation of fatty inclusions were reported by Debeaufort and Voilley [26]. However, an opposite effect was observed by Veiga-Santos et al. [17], suggesting that sucrose molecules form crystals affecting the film-forming matrix, which results in less permeable films. Unlike in this previous work, no emulsifier was used in the present work to stabilize the emulsion. In combination with a high viscosity of the starch slurry and relatively low shear forces applied during the mixing process, the resulting emulsion was possibly coarsely dispersed. It was not verified if the WVP is a function of oil droplet size in the coating material or rather of the specific surface of the hydrophobic phase. Nevertheless, in the current study, it was assumed that sucrose crystallization has a minor effect on WVP compared to the effect of the state of the hydrophobic phase on WVP. With regard to synthetic polymers, the composite cassava starch films used in the present study had WVP values $\left(\times 10^{-7} \mathrm{~g} \mathrm{~Pa}^{-1} \mathrm{~s}^{-1} \mathrm{~m}^{-1}\right)$ higher than those of low-density polyethylenes $\left(0.0036 \times 10^{-10} \mathrm{~g} \mathrm{~Pa}^{-1} \mathrm{~s}^{-1} \mathrm{~m}^{-1}\right)$ [28]. These WVP were also higher than yam starch film permeabilities $\left(2 \times 10^{-10} \mathrm{~g} \mathrm{~Pa}^{-1} \mathrm{~s}^{-1} \mathrm{~m}^{-1}\right)$ [13] and those of other biodegradable films such as tapioca starch/decolorized hsian-tsao leaf gum films $\left(12 \times 10^{-11} \mathrm{~g} \mathrm{~Pa}^{-1} \mathrm{~s}^{-1} \mathrm{~m}^{-1}\right)$ [29]. These high WVP values observed in the present study, compared to other biodegradable films or synthetic films, could be related particularly to the discontinuous and irregular structure of the composite matrix caused by the combined use of sucrose and oil molecules, which might have weakened the water barrier capacity of the resulting films. As sucrose content increasedin the presence of oil, the resulting bulky blend of molecules forming the composite film matrix showed large lipidic inclusions coarsely dispersed. This film matrix could contain porous areas. That might facilitate moisture transfert and could explain why the oil-sucrose-starch films exhibited the least moisture barrier ability as sucrose content was relatively high (15-20 \%). This assertion was also reported by other authors, like Debeaufort and Voilley [26], suggesting 


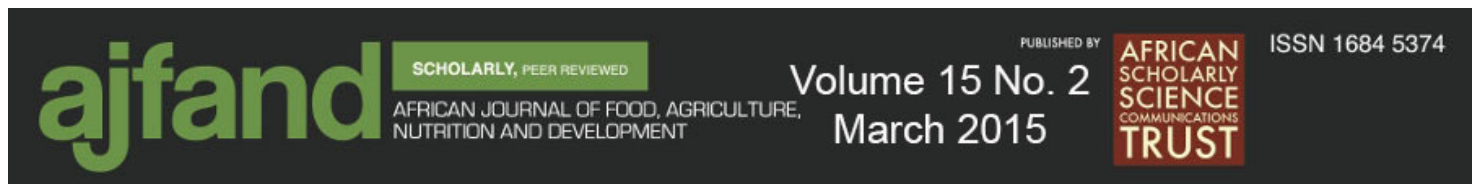

that for polysaccharide-oil film, high drying times could favor coalescence of oil droplets, which generate discontinuities inside the film, and thereby affect the moisture transfert.

\section{CONCLUSION}

Vegetable oil used alone in a proportion of $10 \%$ or in combination with sucrose added at low concentrations (5-10\%) significantly reduced water vapor permeability of films. However, the mechanical properties and WVP were negatively affected as content of added sucrose increased above $10 \%$. The tendency of sucrose to crystallize or the molecular interactions occurring when sucrose and vegetable oil were simultaneously present into the starch matrix led to rough film matrix and heterogeneous structure. Thereby, this structural modification of composite starch matrix weakened mechanical properties and reduced water-tightness of resulting films. Nevertheless, as sucrose and vegetable oil are widely available and cheap texture improvers in edible coatings with a positive effect on the functional properties of the coating. With the help of hydrophobic supplements and plasticizers, the disadvantages of the material, that is brittleness and high WVP, can be controlled. For this purpose, addition of emulsifier is required to improve emulsion stability, which would lead to greater homogeneity of resulting films. Indeed, further investigation is necessary to optimize the microstructure of the films.

\section{ACKNOWLEDGMENTS}

This research was financially supported by Programme d'Appui Stratégique pour la Recherche Scientifique (PASRES, Côte d'Ivoire) and Commission for Research Partnerships with Developing Countries (KFPE, Switzerland). We acknowledge Mrs Katja Morgenstern-Freitag (HES-SO, Switzerland) for technical assistance. 


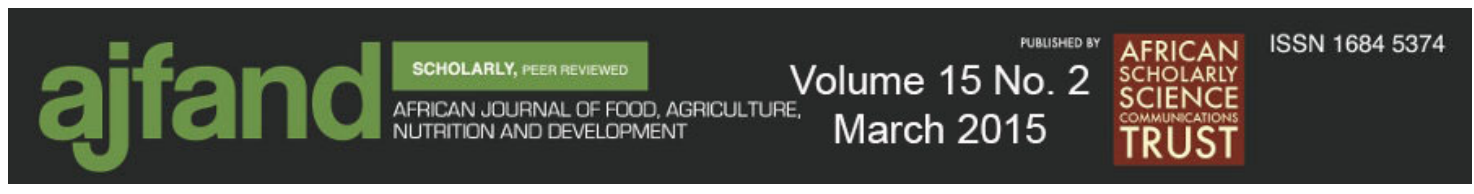

\section{REFERENCES}

1. Li H, Gao X, Wang $\mathbf{Y}$, Zhang $\mathbf{X}$ and Z Tong Comparison of Chitosan/Starch Composite Film Properties before and after Cross-linking. Int. J. Biol. Macromolec. 2013; 52: 275- 279.

2. FAO. Food and Agriculture Organization. In Proceedings of the Validation Forum on the Global Cassava Development Strategy (Vol. 6). International Fund for Agricultural Development, Rome. 2004.

3. Gontard N, Guilbert S and JL Cuq Water and Glycerol as Plasticizers Affect Mechanical and Water Vapor Barrier Properties of an Edible Wheat Gluten Film. J. Food Sci. 1993; 58(1): 206-211.

4. Arvanitoyannis I, Psomiadou E and A Nakayama Edible Films made from Sodium Caseinate, Starches, Sugar or Glycerol. Part 1. Carbohyd. Polym. 1996; 31(2): 179-192.

5. Veiga-santos P, Oliveira LM, Cereda MP, Alves AJ and ARP Scamparini Mechanical properties, hydrophilicity and water activity of starch-gum films: effect of additives and deacetylated xanthan gum. Food Hydrocolloid. 2005; 19(2): 341-439.

6. Morillon V, Debeaufort F, Bond G, Capelle $M$ and A Voilley Factors Affecting the Moisture Permeability of Lipid-Based Edible Films: A Review. Crit. Rev. Food Sci. Nutr. 2002; 42(1): 67-89.

7. Fabra MJ, Jiménez A, Atarés L, Talens $\mathbf{P}$ and A Chiralt Effect of Fatty acids and Beeswax Addition on Properties of Sodium Caseinate Dispersions and Films. Biomacromolecules 2009; 10: 1500-1507.

8. Koelsch CM and TP Labuza Functional, Physiological and Morphological Properties of Methylcellulose and Fatty acid-based Edible Barriers. LWT-Food Sci. Technol. 1992; 25: 404-411.

9. Baldwin EA, Nisperos-Carriedo MO, Hagenmaier RD and RA Baker Use of Lipids in Coatings for Food Products. Food Technol. 1997; 51(6): 56-62.

10. Yang $\mathbf{L}$ and AT Paulson Effects of lipids on mechanical and moisture barrier properties of edible gellan film. Food Res. Int. 2000; 33: 571-578.

11. Jiménez A, Fabra MJ, Talens $\mathbf{P}$ and A Chiralt Effect of lipid self-association on the microstructure and physical properties of hydroxypropyl-methylcellulose edible films containing fatty acids. Carbohyd. Polym. 2010; 82(3): 585-59.

12. Amani NG, Buleon A, Kamenan A and P Colonna Variability in Starch Physicochemical and Functional Properties of Yam (Dioscorea sp) cultivated in Ivory Coast. J. Sci. Food Agr. 2004; 84: 2085-2096. 
13. Mali S, Grossmann MVE, García MA, Martino MN and NE Zaritzky Barrier, mechanical and optical properties of plasticized yam starch films. Carbohyd. Polym. 2004; 56: 129-135.

14. Mali S, Karam LB, Ramos LP and MVE Grossmann Relationships among the composition and physicochemical properties of starches with the characteristics of their films. J. Agric. Food Chem. 2004; 52(25): 7720-7725.

15. Galdeano MC, Mali S, Grossmann MVE, Yamashita F and MA García Effects of plasticizers on the properties of oat starch films. Mat. Sci. Eng. C 2009; 29: 532-538.

16. Mali S, Sakanaka LS, Yamashita F and MVE Grossmann Water sorption and mechanical properties of cassava starch films and their relation to plasticizing effect. Carbohyd. Polym. 2005; 60: 283-289.

17. Veiga-santos P, Oliveira LM, Cereda MP and ARP Scamparini Sucrose and inverted sugar as plasticizer. Effect on cassava starch-gelatin film mechanical properties, hydrophilicity and water activity. Food Chem. 2007; 103: 255-262.

18. García MA, Pinotti A, Martino MN and NE Zaritzky Characterization of composite hydrocolloid films. Carbohyd. Polym. 2004; 56: 339-345.

19. Stansell D. 1995. The composition and structure of confectionery. In: Jackson EB. Sugar confectionary manufacture (2nd ed.). London, UK: Blackie Academic \& Professional, $200 \mathrm{p}$.

20. Poncelet $\mathbf{D}$ and RJ Neufeld Fundamentals of dispersion in encapsulation technology. In: Wijffels R.M., Buitelaar RM, Bucke C and J Tramper (Eds). Immobilized cells. Amsterdam: Elsevier, 1996; 47-55.

21. Chillo S, Flores S, Mastromatteo M, Conte A, Gerschenson L and MA DEL Nobile Influence of glycerol and chitosan on tapioca starch-based edible film properties. J. Food Eng. 2008; 88: 159-168.

22. García MA, Martino MN and NE Zaritzki. Lipid addition to improve barrier properties of starch-based films and coatings. Food Chem. Toxicol. 2000; 65(6): 941-947.

23. Guilbert S and N GONTARD Technology and applications of edible protective films. In: VII Biotechnology and food research-New shelf-life technologies and safety assessments. Helsinki, Finland. 1995; 49-60.

24. Coupland JN, Shaw NB, Monahan FJ, O'Riordan ED and M O'Sullivan Modeling the effect of glycerol on the moisture sorption behavior of whey protein edible films. J. Food Eng. 2000; 43(1): 25-30. 


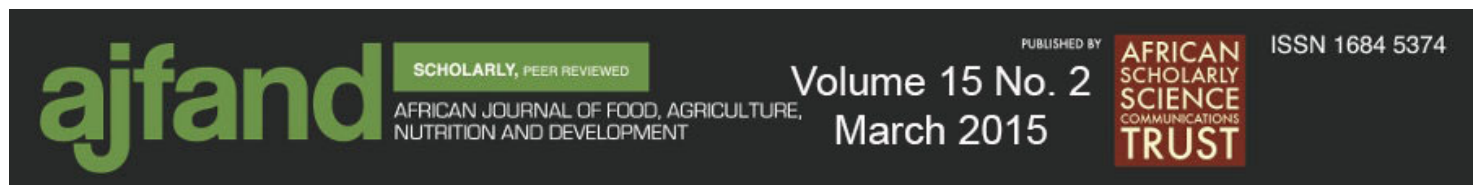

25. Cao N, Yang $\mathbf{X}$ and $\mathbf{Y}$ FU Effects of various plasticizers on mechanical and water vapor barrier properties of gelatin films. Food Hydrocolloid. 2009; 23: 729-735.

26. Debeaufort $\mathbf{F}$ and A Voilley Effect of surfactants and drying rate on barrier properties of emulsified edible films. Int. J. Food Sci. Tech. 1995; 30:183-190.

27. D Stansell The composition and structure of confectionery. In: E. B. Jackson (2nd Ed). Sugar confectionary manufacture. London, UK: Blackie Academic \& Professional, 1995; 200.

28. Shellhammer TH and JM Krochta Whey protein emulsion film performance as affected by lipid type amount. J. Food Sci. 1997; 62(2): 390-394.

29. Chen C-H, Kuo W-S and L-S Lai Effect of surfactants on water barrier and physical properties of tapioca starch/decolorized hsian-tsao leaf gum films. Food Hydrocolloid. 2009; 23: 714-721. 